\title{
Efficacy of wheat-based biscuits fortified with microcapsules containing ferrous sulfate and potassium iodate or a new hydrogen-reduced elemental iron: a randomised, double-blind, controlled trial in Kuwaiti women
}

\author{
Ralf Biebinger ${ }^{1}$, Michael B. Zimmermann ${ }^{1}$, Suad N. Al-Hooti ${ }^{2}$, Nawal Al-Hamed ${ }^{3}$, Ebtehal Al-Salem ${ }^{4}$, \\ Tasleem Zafar ${ }^{5}$, Yearul Kabir ${ }^{5}$, I'nam Al-Obaid ${ }^{6}$, Nicolai Petry ${ }^{1}$ and Richard F. Hurrell ${ }^{1 *}$ \\ ${ }^{1}$ The Human Nutrition Laboratory, Institute of Food Science and Nutrition, ETH Zurich, CH-8092 Zurich, Switzerland \\ ${ }^{2}$ Kuwait Institute for Scientific Research, Kuwait City, Kuwait \\ ${ }^{3}$ Ministry of Health, Kuwait City, Kuwait \\ ${ }^{4}$ Kuwait Flour Mills and Bakeries Company, Safat, Kuwait City, Kuwait \\ ${ }^{5}$ College for Women, Kuwait University, Kuwait \\ ${ }^{6}$ Sabah Hospital, Ministry of Health, Kuwait City, Kuwait \\ (Received 23 June 2008 - Revised 30 April 2009 - Accepted 1 May 2009 - First published online 5 August 2009)
}

\begin{abstract}
Adverse sensory changes prevent the addition of highly bioavailable ferrous sulfate $\left(\mathrm{FeSO}_{4}\right)$ to most wheat flours. Poorly absorbable reduced Fe powders are commonly used. Encapsulation of $\mathrm{FeSO}_{4}$ can overcome these sensory changes, but the particle size of commercial compounds is too large to be used by flour mills. The first objective of the study was to measure the efficacy in wheat flour of two newly developed Fe compounds, an H-reduced Fe powder (NutraFine ${ }^{\mathrm{TM}} \mathrm{RS}$; North America Höganäs High Alloys LLC, Johnstown, PA, USA) and small particle-sized (40 $\mu \mathrm{m}$ ) encapsulated $\mathrm{FeSO}_{4}$. As a second objective, the microcapsules were evaluated as a vehicle for iodine fortification. A randomised, double-blind controlled intervention trial was conducted in Kuwaiti women ( $n$ 279; aged $18-35$ years) with low body Fe stores (serum ferritin $(\mathrm{SF})<25 \mu \mathrm{g} / \mathrm{l})$ randomly assigned to one of three groups $\left(20 \mathrm{mg} \mathrm{Fe}\right.$ as NutraFine ${ }^{\mathrm{TM}} \mathrm{RS}, 10 \mathrm{mg} \mathrm{Fe}$ as encapsulated $\mathrm{FeSO}_{4}$ and $150 \mu \mathrm{g}$ iodine, or no fortification $\mathrm{Fe}$ ) who consumed wheat-based biscuits $5 \mathrm{~d}$ per week. At baseline and 22 weeks, $\mathrm{Hb}$, SF, transferrin receptor, urinary iodine and body Fe stores were measured. Relative to control, mean $\mathrm{SF}$ in the encapsulated $\mathrm{FeSO}_{4}$ group increased by $88 \%(P<0 \cdot 001)$ and body Fe stores increased from -0.96 to $2.24 \mathrm{mg} / \mathrm{kg}$ body weight $(P<0.001)$, while NutraFine ${ }^{\mathrm{TM}} \mathrm{RS}$ did not significantly increase SF or body Fe stores. The median urinary iodine concentration increased from 140 to $213 \mu \mathrm{g} / \mathrm{l}(P<0 \cdot 01)$. NutraFine ${ }^{\mathrm{TM}} \mathrm{RS}$ added at double the amount of $\mathrm{Fe}$ as $\mathrm{FeSO}_{4}$ was not efficacious in improving Fe status. The newly developed microcapsules were highly efficacious in improving both Fe stores and iodine status.
\end{abstract}

Iron fortification: Iron-deficiency anaemia: Iodine fortification: Intervention trials: Women

Fe-deficiency anaemia and iodine-deficiency disorders are common in children and women of childbearing age in both developing and industrialised countries ${ }^{(1,2)}$. Food fortification is considered to be the most cost-effective, long-term, population-based strategy to combat micronutrient malnutrition $^{(1,3,4)}$. Worldwide, cereals are the foods most often fortified with $\mathrm{Fe}$ and other micronutrients, although iodine has been traditionally added to salt. The USA, Canada, the UK, and several Latin American, African, Middle East and Central Asia countries require Fe to be added to low-extraction wheat flour ${ }^{(5,6)}$. Many countries also have mandatory iodine fortification of salt ${ }^{(7,8)}$.

Unfortunately, the well-absorbed, water-soluble $\mathrm{Fe}$ compounds, such as ferrous sulfate $\left(\mathrm{FeSO}_{4}\right)$, may cause sensory changes in stored wheat flours ${ }^{(4,9)}$, and therefore the less soluble $\mathrm{Fe}$ compounds, such as elemental Fe powders, have been commonly used for cereal fortification. They are relatively inexpensive and cause fewer organoleptic problems compared with ferrous sulfate or other soluble Fe compounds ${ }^{(4,5)}$. However, most elemental Fe powders are poorly absorbed. Electrolytic Fe and reduced Fe are the elemental $\mathrm{Fe}$ powders most commonly added to wheat flour. WHO guidelines $^{(1)}$ recommend electrolytic Fe as the only elemental Fe powder to be used in food fortification and recommend that it should be added to wheat flour at twice the level of ferrous sulfate so as to compensate for its lower bioavailability. The WHO guidelines further consider that $\mathrm{Fe}$ absorption from $\mathrm{H}$-reduced $\mathrm{Fe}$ powders is too low for it to be recommended for wheat flour fortification but they recommend that $\mathrm{H}$-reduced $\mathrm{Fe}$ could be reconsidered as a fortificant after further studies.

Encapsulation of ferrous sulfate can reduce Fe-mediated sensory changes in foods ${ }^{(10)}$ and is recommended by WHO for fortification of wheat flour ${ }^{(1)}$. However, commercially

Abbreviations: CfW, College for Women, Kuwait University; NC, Nursing College, Public Authority for Applied Education and Training; SF, serum ferritin. * Corresponding author: Professor Richard F. Hurrell, fax + 4144632 1470, email Richard.Hurrell@ilw.agrl.ethz.ch 
available products are too large to be used by most flour mills, because they will not pass the small sieve diameters used in the final stages of processing. The fat-based capsule used to enrobe the $\mathrm{Fe}$ is a useful carrier of other micronutrients and offers some protection against storage and processing losses. We have previously shown that fat-based microcapsules containing $\mathrm{Fe}$ and iodine improve $\mathrm{Fe}$ and iodine status when used to fortify salt. Double fortification of foods with $\mathrm{Fe}$ and iodine may be particularly beneficial because Fe-deficiency anaemia reduces the efficacy of iodine prophylaxis ${ }^{(10-12)}$.

Although salt iodisation is the preferred strategy for iodine prophylaxis $^{(1)}$, it is ineffective where salt is not the major condiment (for example, in Southeast Asia, where it is replaced by soya and fish sauce) or where the presence of multiple small salt producers makes installation of fortification infrastructure difficult. In these situations, alternate vehicles for iodine should be explored ${ }^{(13)}$. Wheat flour could be a valuable alternative vehicle for iodine fortification and encapsulation could help ensure iodine stability.

An efficacy study in Thailand ${ }^{(14)}$ with Fe-fortified wheat flour snacks fed to women for $6 \mathrm{~d}$ per week over 35 weeks reported that electrolytic Fe (A-131; North America Höganäs High Alloys LLC, Johnstown, PA, USA) and H-reduced $\mathrm{Fe}$ (AC-325; North America Höganäs High Alloys LLC) had efficacies of 77 and $49 \%$, respectively, relative to ferrous sulfate. Encouraged by the relatively high efficacy of the commercial H-reduced Fe AC-325, the manufacturer Höganäs attempted to further improve the bioavailability of their $\mathrm{H}$-reduced $\mathrm{Fe}$ powder by modifying the manufacturing process so as to increase the porosity of the Fe powder and its solubility in dilute $\operatorname{acid}^{(15)}$. The newly developed H-reduced $\mathrm{Fe}$ powder has been commercialised under the name NutraFine $^{\mathrm{TM}}$ RS.

The present efficacy study was thus designed to evaluate two newly developed $\mathrm{Fe}$ compounds for wheat flour fortification: an H-reduced Fe powder (NutraFine ${ }^{\mathrm{TM}} \mathrm{RS}$ ) and small particle-sized encapsulated ferrous sulfate. By incorporating potassium iodate into the lipid shell of the microcapsules, their potential for iodine fortification was also investigated. The capsules had a mean particle size of approximately $40 \mu \mathrm{m}$ and should not be retained by the sieves in the flour mill. The study was carried out in young women in Kuwait over a 22-week period during which they regularly consumed $\mathrm{Fe}-$ and $\mathrm{Fe} /$ iodine-fortified wheat flour biscuits and their $\mathrm{Fe}$ and iodine status was monitored.

\section{Materials and methods}

\section{Hydrogen-reduced iron powder}

H-reduced $\mathrm{Fe}$ (NutraFine $^{\mathrm{TM}} \mathrm{RS}$, mean particle size $\left(\mathrm{d}_{50}\right)$ approximately equal to $30 \mu \mathrm{m}$ ) was manufactured by North America Höganäs High Alloys LLC. The manufacturer modified the traditional manufacturing process to produce an Fe powder of greater porosity and a $20 \%$ greater solubility in dilute acid as compared with the previously marketed $\mathrm{H}$-reduced $\mathrm{Fe}$ powder (AC-325). It was assumed that a greater solubility rate in dilute acid would improve Fe absorption in human subjects ${ }^{(15)}$. It should be noted that the vast majority of Fe powders are manufactured to meet the needs of the automobile industry and that only a small surplus of these powders is used for food fortification. NutraFine ${ }^{\text {TM }} \mathrm{RS}$ is the first Fe powder developed exclusively for food fortification.

\section{Microcapsules containing iron and iodine}

A single-step, spray-cooling technique previously described for salt fortification was modified and optimised to build microcapsules containing $\mathrm{Fe}$ and iodine for wheat flour fortification ${ }^{(16)}$. The components for the capsule were micronised $\mathrm{FeSO}_{4}$ monohydrate with a mean particle size $\left(\mathrm{d}_{50}\right)$ of $<5 \mu \mathrm{m}$ (Dr Paul Lohmann GmbH KG, Emmerthal, Germany) and potassium iodate (Riedel-de Haen, Hannover, Germany). The Fe and iodine were coated with hydrogenated palm oil (Rau Fette, Neuss, Germany) with a melting point of $65^{\circ} \mathrm{C}$.

For the capsules to be suitable for wheat flour fortification, a $\mathrm{d}_{90}<150 \mu \mathrm{m}$ is required in order to pass through the sieves $(150 \mu \mathrm{m})$ commonly used by the milling industry. Also, the Fe compound:capsule ratio should be $\geq 50: 50$ to ensure $\mathrm{Fe}$ bioavailability $^{(10)}$. To meet this requirement, several changes were made in our previously published spray-cooling process $^{(16)}$. The highly viscous suspension of fat, ferrous sulfate, potassium iodate and emulsifiers was heated to $85 \pm 5^{\circ} \mathrm{C}$ and then passed via a piston pump (Rotary piston pump; CATAG AG, Basel, Switzerland) into a stainless-steel, cold-spraying tower (Schidlin AG, Zurich, Switzerland), atomised with a two-fluid nozzle (SSCO-Spraying Systems AG, Pfäffikon SZ, Switzerland) using air as the second medium, and then cooled with the use of partially evaporated liquid $\mathrm{N}_{2}$. The final spraying parameters used were: pump water temperature, $82.5^{\circ} \mathrm{C}$; tower water temperature, $90.5^{\circ} \mathrm{C}$; air temperature, $90^{\circ} \mathrm{C}$; pump pressure, 2.0 bars; tower cooling temperature, $-40 \pm 5^{\circ} \mathrm{C}$.

\section{Production of fortified wheat flour-based biscuits}

Wheat flour biscuits ('Petite Beurre') were manufactured in $200 \mathrm{~kg}$ batches from a slightly modified standard commercial recipe at the Kuwaiti Flour Mills and Bakeries Company using unfortified low-extraction flour. The recipe per $\mathrm{kg}$ flour was as follows: sugar, $275 \mathrm{~g}$; ghee, $125 \mathrm{~g}$; dextrose, $25 \mathrm{~g}$; flavours, $15 \mathrm{~g}$; baking agents, $14.3 \mathrm{~g}$; egg yolk, $10 \mathrm{~g}$; salt, $7.5 \mathrm{~g}$; malt, $4 \mathrm{~g}$; water, $200 \mathrm{~g}$. To ensure a homogeneous mixture of microcapsules and wheat flour, $10 \mathrm{~kg}$ wheat flour was premixed with the appropriate amount of microcapsules or H-reduced Fe before adding the remaining ingredients. One package of four biscuits (each biscuit weighing 6.25 g) was designed to provide $10 \mathrm{mg}$ added $\mathrm{Fe}$ as encapsulated $\mathrm{FeSO}_{4}$ and $150 \mu \mathrm{g}$ iodine or $20 \mathrm{mg}$ NutraFine ${ }^{\mathrm{TM}} \mathrm{RS}$. Due to the high Fe dose in the fortified biscuits used for the intervention study, sodium citrate was added at a 5:1 molar ratio to reduce the metallic flavour and maintain the shelf life; this amount of citrate was also added to identical non-fortified biscuits. During the feeding trial, the biscuits were produced at 0,8 and 16 weeks in colour- and letter-coded batches under close supervision. They were stored under controlled conditions following the quality standards for temperature and humidity at the Kuwaiti Flour Mills and Bakeries Company and transported on demand to the study sites. 


\section{Sensory testing}

Wheat flour fortified with the test compounds was stored for 3 months at 50 and $75 \%$ relative humidity and 25 and $37^{\circ} \mathrm{C}$ and $\mathrm{Fe}$-mediated colour changes were investigated in the flour. Potential sensory changes in the biscuits were evaluated using triangle tests performed in Kuwaiti and Swiss adults (twenty-four subjects at each site). During the triangle test, three coded samples (two control unfortified samples plus one test Fe-fortified sample) of the biscuits were given in a random order in a private setting. The panellists were asked to indicate which sample differed in colour, flavour or texture from the other two samples.

\section{Solubility and $X$-ray diffraction studies}

H-reduced Fe (AC-325; North America Höganäs High Alloys LLC), electrolytic Fe (A-131; North America Höganäs High Alloys LLC) and $\mathrm{FeSO}_{4}$ monohydrate (Crown Technology, Indianapolis, IN, USA) were obtained from the SUSTAIN Fe pool, which was used for a recent comparison of different elemental $\mathrm{Fe}$ powders ${ }^{(15)}$. These compounds were compared with NutraFine $^{\mathrm{TM}}$ RS in a series of in vitro solubility tests. The solubility of elemental Fe powders in dilute acid was tested as described previously ${ }^{(15)}$. A total of $20 \mathrm{mg} \mathrm{Fe}$ was added to $250 \mathrm{ml}$ aqueous solution of $0.1 \mathrm{M}-\mathrm{HCl}$ corresponding to $\mathrm{pH} 1$ and mixed in an orbital shaker at $150 \mathrm{rpm}$ and $37^{\circ} \mathrm{C}$ (Aqua shaker; Adolf Kühner, Basel, Switzerland). The percentage of dissolved Fe was measured in a $1.5 \mathrm{ml}$ sample after 15 , 30 and $60 \mathrm{~min}$.

After centrifugation for $4 \mathrm{~min}$ at $11600 \mathrm{~g}$, the Fe content of the supernatant fraction solution was measured by atomic absorption spectroscopy. The elemental Fe powder X-ray diffraction patterns were recorded with a Bruker D8 Advance $(40 \mathrm{kV} ; 40 \mathrm{~mA} ; \lambda=1.54 \mathrm{~nm})$ at a scan speed of $0.5 \% \mathrm{~min}$ and $10^{\circ}<2 \mathrm{q}<70^{\circ}$.

\section{Efficacy study}

The feeding study was carried out in Kuwait City, the capital of the State of Kuwait.

\section{Subjects and study design}

Women aged 18-35 years were recruited from two colleges in Kuwait - College for Women, Kuwait University (CfW) and the Nursing College, Public Authority for Applied Education $\&$ Training (NC). The present study was conducted according to the guidelines laid down in the Declaration of Helsinki and all procedures involving human subjects were approved by the ethical committees of the Swiss Federal Institute of Technology in Zurich and the Ministry of Health in Kuwait. Written informed consent was obtained from all subjects; if subjects were aged less than 21 years, consent was obtained from their parents.

Blood was drawn from the volunteers and serum ferritin (SF) measured. Subjects were invited to join the intervention trial if: (1) they had low Fe stores, defined as a SF concentration $<25$ $\mu \mathrm{g} / \mathrm{l}$; (2) were not pregnant or planning pregnancy; (3) had no chronic medical illnesses; (4) did not use vitamin and mineral supplements. Subjects meeting the inclusion criteria were randomly assigned to three groups receiving biscuits fortified with either H-reduced Fe (NutraFine ${ }^{\mathrm{TM}} \mathrm{RS}$ ) or encapsulated $\mathrm{FeSO}_{4}$ and potassium iodate or the non-fortified biscuits. The biscuits were consumed $5 \mathrm{~d}$ per week in the morning pause between lectures at the colleges. If a subject was absent from college, the missed pack of biscuits was compensated by provision of two packs of biscuits the following day. Subjects were instructed to consume the biscuits at least $1 \mathrm{~h}$ away from meals and without coffee and tea; only water was provided with the biscuits. On scheduled holidays, the subjects were provided with a sufficient amount of biscuits, packaged into individual daily portions, and instructed to consume a pack of biscuits each day away from meals and to report if they were not consumed.

At baseline and endpoint, weight and height were measured, and a spot urine sample was collected for measurement of urinary iodine concentration of those subjects who accepted to be part of the iodine pilot study. Whole blood was collected by venepuncture for measurement of $\mathrm{Hb}, \mathrm{SF}$, serum transferrin receptor and C-reactive protein. The study design was randomised double blind and the intervention period was from December 2006 to May 2007.

\section{Laboratory analysis}

Blood samples were transported on ice to Al-Sabah Hospital in Kuwait City. Hb was measured in whole blood (refrigerated and measured on the same day of collection) with the use of a haematology analyser (Cell-Dyn 4000; Abbott Diagnostics, Abbott Park, IL, USA) with three-level control material provided by the manufacturer. Blood was centrifuged on the day of collection, and the serum was divided into samples and frozen at $-60^{\circ} \mathrm{C}$. SF was measured using RIA (Ramco, Houston, TX, USA), and transferrin receptor concentrations were measured using ELISA-immunoassays (Ramco). High-sensitivity C-reactive protein was measured with a BN Pro Spec analyser (Dade Behring, Newark, DE, USA). Urinary iodine samples were sampled and frozen at $-20^{\circ} \mathrm{C}$ and were measured using the Sandell-Kolthoff reaction as modified by Pino et al. ${ }^{(17,18)}$. The phytic acid content of the baked snacks was measured by the modified Makower method ${ }^{(19)}$. Anaemia was defined as $\mathrm{Hb}<120 \mathrm{~g} / \mathrm{l}$. Fe deficiency was defined as SF $<15 \mu \mathrm{g} / \mathrm{l}$. The cut-off for serum transferrin receptor was set at $>8.5 \mathrm{ng} / \mathrm{ml}$. Fe-deficiency anaemia was defined as anaemia and Fe deficiency by the above-mentioned criteria ${ }^{(1)}$. Body Fe was estimated from the transferrin receptor:SF ratio ${ }^{(20)}$. SF measurements from subjects with elevated C-reactive protein $(>10 \mathrm{mg} / \mathrm{l})$ were excluded from the statistical analysis. The iodine content of the snacks and the microcapsules was measured by inductively coupled plasma MS (Thermo Finnigan, San Jose, CA, USA) ${ }^{(21)}$ or X-ray fluorescence (PANalytical, Almelo, The Netherlands; http://www.paralytical.com/index.cfm?pid=283), respectively. The Fe content of the baked snacks and the microcapsules was measured by atomic absorption spectroscopy (Spectra AA-50; Varian, Palo Alto, CA, USA). The particle size of the Fe compounds was measured using laser diffraction spectrometry (Malvern Mastersizer X; Rennes, Lausanne, Switzerland), and microcapsule morphology determined by scanning electron microscopy (S 900; Hitachi, Tokyo, Japan). To measure colour changes, $10 \mathrm{~g}$ fortified flour was transferred into a glass container; colour determination on the Hunter scale was 
established with the use of a Spectral Photometer (Chroma Meter CR-310; Minolta, Osaka, Japan) by using an illuminant D65 (average daylight, including UV spectra) setting and a $0^{\circ}$ observer angle with a large reflectance spectrum as previously described $^{(16,22)}$.

\section{Statistical analyses}

Data processing and analysis were performed using Microsoft Excel 2002 (Redmond, WA, USA) and SPSS 13.0 (SPSS Inc., Chicago, IL, USA). Data which were not normally distributed (SF) were $\log$ transformed. Solubility data were compared by unpaired $t$ tests. Two-way ANOVA (time $\times$ treatment) were used to compare groups with Bonferroni post hoc testing.

For binary variables (Fe deficiency prevalence), $\chi^{2}$ tests were used to compare groups. Significance was set at $P<0 \cdot 05$.

\section{Results}

\section{Solubility in dilute acid and $X$-ray diffraction of elemental iron powders}

The results of the solubility of the elemental Fe powders in $0 \cdot 1 \mathrm{M}-\mathrm{HCl}$ are shown Table 1 . Dried ferrous sulfate was virtually $100 \%$ soluble after $15 \mathrm{~min}$. After $30 \mathrm{~min}$, NutraFine $^{\mathrm{TM}}$ RS was $33.6 \%$ soluble compared with $26.9 \%$ solubility for AC-325 H-reduced Fe and 71.6\% solubility for electrolytic Fe. The newly developed NutraFine ${ }^{\mathrm{TM}}$ RS thus showed a $20 \%$ better solubility than the previous commercial H-reduced $\mathrm{Fe}$ (AC-325) but was still $40 \%$ less soluble in dilute acid than electrolytic Fe (A-131). The X-ray diffraction patterns (data not shown) indicated that H-reduced Fe (NutraFine $\left.^{\mathrm{TM}} \mathrm{RS}\right)$ and electrolytic Fe (A-131) contained less iron oxide as impurities than H-reduced Fe (AC-325).

\section{Microcapsule characteristics}

The capsules had a mean particle size of approximately $40 \mu \mathrm{m}$ and the microcapsule:substrate ratio was approximately 50:50. The mean Fe content of the microcapsule was 15.7 (SD 0.4) \% and the iodine content was 0.45 (SD 0.02) \%. During spraying, mean iodine losses were about $25 \%$; wheat flour storage and the baking process produced no measurable iodine losses.

Table 1. Relative solubility of different elemental iron compounds* (Mean values and standard deviations for three independent replicates)

\begin{tabular}{|c|c|c|c|c|c|c|}
\hline \multirow[b]{3}{*}{ Time (min) } & \multicolumn{6}{|c|}{ Solubility in dilute acid (\%) } \\
\hline & \multicolumn{2}{|c|}{$\begin{array}{l}\text { H-reduced } \\
(\text { AC-325)† }\end{array}$} & \multicolumn{2}{|c|}{$\begin{array}{c}\text { NutraFine }^{\mathrm{TM}} \\
\text { RS } †\end{array}$} & \multicolumn{2}{|c|}{$\begin{array}{c}\text { Electrolytic } \\
(A-131) \dagger\end{array}$} \\
\hline & Mean & SD & Mean & SD & Mean & SD \\
\hline 15 & $21 \cdot 3^{a}$ & 2.9 & $23 \cdot 7^{\mathrm{a}}$ & 3.4 & $54 \cdot 7^{b}$ & $7 \cdot 3$ \\
\hline 30 & $26 \cdot 9^{a}$ & 0.2 & $33 \cdot 6^{\mathrm{b}}$ & 1.8 & $71 \cdot 6^{c}$ & 2.9 \\
\hline 60 & $35 \cdot 7^{\mathrm{a}}$ & 0.8 & $50 \cdot 8^{b}$ & 0.3 & $93 \cdot 4^{\mathrm{c}}$ & 0.6 \\
\hline
\end{tabular}

\section{Sensory evaluations}

In the flour storage trial, no significant difference in colour could be detected after 3 months at different temperatures and humidity conditions (data not shown). In the triangle testing in both Kuwait and Switzerland, the fortified biscuits were indistinguishable from the non-fortified biscuits in colour, taste and texture.

\section{Composition of biscuits}

The mean Fe content was 0.35 (SD 0.05) mg per snack of $25 \mathrm{~g}$ for the control biscuits, $10 \cdot 2$ (SD 0.9) $\mathrm{mg}$ per snack of $25 \mathrm{~g}$ for the encapsulated $\mathrm{FeSO}_{4}$ biscuits and 20.1 (SD 0.9) mg per snack of $25 \mathrm{~g}$ for the H-reduced Fe (NutraFine ${ }^{\mathrm{TM}} \mathrm{RS}$ ) biscuits. The mean phytic acid content of the biscuits was 59 (SD 2) $\mathrm{mg}$ per $100 \mathrm{~g}$ and mean iodine content was 130 (SD 9) $\mu \mathrm{g}$ per snack of $25 \mathrm{~g}$. Fe content was checked for each batch with no significant difference between the batches. Weight control of the biscuits was conducted during production, and packaging was started only after reaching optimal production conditions.

\section{Human efficacy trial}

Table 2 shows the baseline characteristics of the screened and selected subjects; a total of 279 out of 383 subjects met the inclusion criteria and were randomly assigned to three groups of ninety-three (control: CfW group, $n$ 53; $\mathrm{NC}$ group, $n$ 40; NutraFine ${ }^{\mathrm{TM}} \mathrm{RS}$ : CfW group, $n$ 47; NC group, $n$ 46; microcapsules: CfW group, $n$ 55; NC group, $n$ 38). There were no significant differences among the three groups in baseline anthropometrics, mean $\mathrm{Hb}, \mathrm{SF}$ or serum transferrin receptor.

A total of $65 \%$ of the screened subjects completed the $\mathrm{Fe}$ fortification efficacy study (control, $n 61$ (CfW group, $n$ 37; NC group, $n$ 24); NutraFine ${ }^{\mathrm{TM}} \mathrm{RS}, n 63$ (CfW group, $n$ 28; $\mathrm{NC}, n$ 35); microcapsules, $n 57$ (CfW group, $n$ 32; NC group, $n$ 25)). Drop-outs were due to: (1) time constraints (72\%); (2) changing residence (14\%); (3) illness $(8 \%)$; (4) pregnancy $(6 \%)$. There were no significant differences in baseline anthropometrics, Hb or SF characteristics comparing the students by group who completed the study with those who dropped out (data not shown).

In Table 3, the changes in $\mathrm{Hb}, \mathrm{SF}$, serum transferrin receptor and body $\mathrm{Fe}$ stores are presented. There was no significant change in $\mathrm{Hb}$ or the prevalence of anaemia in any group during the study. Mean SF significantly increased from 10.5 (SD 6.5) $\mu \mathrm{g} / \mathrm{l}$ at baseline to 19.8 (SD 10.5) $\mu \mathrm{g} / \mathrm{l}$ after 22 weeks $(P<0.001)$ and body $\mathrm{Fe}$ stores from -0.96 to $2.24 \mathrm{mg} / \mathrm{kg}$ body weight $(P<0.001)$ in the ferrous sulfate microcapsule group, which was also significantly higher as compared with the control group $(P<0 \cdot 05)$. In contrast, NutraFine $^{\mathrm{TM}}$ RS did not significantly increase SF or body Fe stores as compared with the control group.

A total of $46 \%$ ( $n$ 129) of the subjects in the Fe fortification efficacy study accepted to participate in the iodine fortification efficacy pilot study. Inclusion of the potassium iodate in the capsule ( $n$ 44) significantly increased the median urinary iodine from a baseline concentration of 140 (range 10-681) to 213 (range 22-881) $\mu \mathrm{g} / \mathrm{l}$ after 22 weeks, while there was 
Table 2. Characteristics of screened ( $n$ 383) and selected ( $n$ 279) Kuwaiti college women at baseline screening

(Mean values and standard deviations or percentage prevalences)

\begin{tabular}{|c|c|c|c|c|}
\hline \multirow[b]{2}{*}{ Characteristics } & \multicolumn{2}{|c|}{ Screened } & \multicolumn{2}{|c|}{ Selected } \\
\hline & Mean & SD & Mean & SD \\
\hline Age (years) & $20 \cdot 6$ & $3 \cdot 1$ & $20 \cdot 1$ & $3 \cdot 2$ \\
\hline Height $(\mathrm{cm})$ & $159 \cdot 8$ & $5 \cdot 6$ & $159 \cdot 9$ & $5 \cdot 5$ \\
\hline Weight (kg) & $63 \cdot 8$ & $15 \cdot 9$ & 63.7 & $15 \cdot 0$ \\
\hline $\operatorname{BMI}\left(\mathrm{kg} / \mathrm{m}^{2}\right)$ & 24.9 & $5 \cdot 6$ & 24.8 & 5.4 \\
\hline $\mathrm{Hb}(\mathrm{g} / \mathrm{l})$ & $130 \cdot 9$ & $10 \cdot 4$ & $130 \cdot 1$ & $10 \cdot 7$ \\
\hline Serum ferritin $(\mu \mathrm{g} / \mathrm{l})$ & $18 \cdot 9$ & $17 \cdot 7$ & $10 \cdot 9$ & $6 \cdot 8$ \\
\hline Transferrin receptor $(\mathrm{mg} / \mathrm{l})$ & $6 \cdot 9$ & $2 \cdot 7$ & $7 \cdot 3$ & $2 \cdot 8$ \\
\hline Body Fe stores (mg Fe/kg body weight) & 0.9 & 4.0 & -0.7 & 3.5 \\
\hline Anaemia prevalence $(\%)$ & \multicolumn{2}{|c|}{15} & \multicolumn{2}{|c|}{15} \\
\hline Prevalence of low Fe status (serum ferritin < $25 \mu \mathrm{g} / \mathrm{l}$ ) (\%) & \multicolumn{2}{|c|}{77} & \multicolumn{2}{|c|}{100} \\
\hline Prevalence of Fe deficiency (serum ferritin $<15 \mu \mathrm{g} / \mathrm{l}$ ) (\%) & \multirow{2}{*}{\multicolumn{2}{|c|}{$\begin{array}{l}50 \\
14\end{array}$}} & \multirow{2}{*}{\multicolumn{2}{|c|}{24}} \\
\hline Prevalence of serum transferrin receptor $>8.5 \mathrm{mg} / \mathrm{l}(\%)$ & & & & \\
\hline
\end{tabular}

no significant change in the median urinary iodine concentration in the control group ( $n$ 43) (138 (range 9-470) $\mu \mathrm{g} / \mathrm{l}$ ). The urine of the subjects who consumed biscuits with NutraFine $^{\mathrm{TM}}$ RS was not analysed ( $n$ 42).

\section{Discussion}

Despite a high standard of living, the prevalence of anaemia $(15 \%)$ and $\mathrm{Fe}$ deficiency $(50 \%)$ was relatively high in young female Kuwaiti students (Table 2). These prevalence values are, however, lower than those previously reported. Eid et al. reported $26 \%$ anaemia in Kuwaiti girls aged 6-17 years $^{(23)}$, Al-Awadi et al. reported $23 \%$ anaemia in Kuwaiti females aged $14-45$ years $^{(24)}$ and, most recently, Jackson \& Al-Mousa found $30 \%$ anaemia and $68 \%$ Fe deficiency (as measured by erythrocyte protoporphyrin) in Kuwaiti girls aged $14-23$ years $^{(25)}$. These studies were all made before the introduction of the flour fortification programme in 2001. Since that date, wheat flour in Kuwait has been fortified with 60 parts per million of reduced Fe powder manufactured by the atomisation process, providing on average an extra $12 \mathrm{mg} \mathrm{Fe} /$ person per $\mathrm{d}$ in an average flour consumption of about $200 \mathrm{~g} /$ person per d. As there is only one flour mill in Kuwait, all of the wheat flour is fortified. However, the

Table 3. $\mathrm{Hb}$, serum ferritin, serum transferrin receptor, body iron stores and prevalence of iron deficiency at baseline and 22 weeks

(Mean values and standard deviations or percentage prevalences)

\begin{tabular}{|c|c|c|c|c|c|c|}
\hline & \multicolumn{2}{|c|}{ Control } & \multicolumn{2}{|c|}{$\begin{array}{c}\text { Encapsulated } \\
\mathrm{FeSO}_{4}+\text { iodine } \|\end{array}$} & \multicolumn{2}{|c|}{ NutraFine $^{\mathrm{TM}} \mathrm{RS} \|$} \\
\hline & Mean & SD & Mean & SD & Mean & SD \\
\hline \multicolumn{7}{|l|}{$\mathrm{Hb}(\mathrm{g} / \mathrm{l})$} \\
\hline Baseline & 128 & 11 & 131 & 10 & 131 & 10 \\
\hline 22 weeks & 125 & 11 & 131 & 9 & 129 & 9 \\
\hline \multicolumn{7}{|c|}{ Serum ferritin $(\mu \mathrm{g} / \mathrm{I})^{\star \star}$} \\
\hline Baseline & $11 \cdot 2$ & $7 \cdot 1$ & $10 \cdot 5$ & $6 \cdot 5$ & $11 \cdot 1$ & $7 \cdot 1$ \\
\hline 22 weeks & $15 \cdot 1^{\mathrm{a}}+\dagger$ & $7 \cdot 1$ & $19 \cdot 8^{\mathrm{b}}+\dagger \dagger$ & $10 \cdot 5$ & $14 \cdot 6^{\mathrm{a}}+\dagger$ & $10 \cdot 6$ \\
\hline \multicolumn{7}{|c|}{ Serum transferrin receptor $(\mathrm{mg} / \mathrm{l})^{\star \star}$} \\
\hline Baseline & $7 \cdot 1$ & $3 \cdot 1$ & $7 \cdot 5$ & 4.9 & $7 \cdot 2$ & $2 \cdot 6$ \\
\hline 22 weeks & $7 \cdot 5^{\mathrm{a}}$ & 4.9 & $6 \cdot 0^{\mathrm{b}}+\dagger$ & 1.5 & $6 \cdot 7^{\mathrm{a}}$ & $2 \cdot 1$ \\
\hline \multicolumn{7}{|c|}{ Body Fe status (mg Fe/kg body weight) ${ }^{\star \star}$} \\
\hline Baseline & -0.48 & 3.4 & -0.96 & $3 \cdot 4$ & -0.60 & $3 \cdot 7$ \\
\hline 22 weeks & $0.35^{\mathrm{a}}$ & 3.96 & $2 \cdot 24^{\mathrm{b}}+\dagger \dagger$ & 1.49 & $0.49^{\mathrm{a}}$ & 3.4 \\
\hline \multicolumn{7}{|c|}{ Prevalence of Fe deficiency (serum ferritin $<15 \mu \mathrm{g} / \mathrm{l}$ ) $(\%)$} \\
\hline Baseline & \multicolumn{2}{|c|}{70} & \multicolumn{2}{|c|}{72} & \multicolumn{2}{|c|}{70} \\
\hline 22 weeks & \multicolumn{2}{|c|}{57 㧊 } & \multicolumn{2}{|c|}{ 42‡‡§§ } & \multicolumn{2}{|c|}{58 5† } \\
\hline
\end{tabular}

a,b Mean values within a row with unlike superscript letters were significantly different $(P<0.05$; ANOVA). ** Significant treatment $\times$ time interaction $(P<0.01$; ANOVA).

Mean value was significantly different from that at baseline: t† $P<0.01$, t†† $P<0.001$.

抽 Prevalence was significantly different from that at baseline $\left(P<0.01 ; \chi^{2}\right.$ test $)$.

$\S \S$ Prevalence was significantly different from that of the control group $\left(P<0.01 ; \chi^{2}\right.$ test $)$.

$\|$ NutraFine $^{\mathrm{TM}}$ RS was manufactured by North America Höganäs High Alloys LLC (Johnstown,

$\mathrm{PA}$, USA). For details of the $\mathrm{FeSO}_{4}+$ iodine microcapsules, see the Microcapsules containing iron and iodine section. 
atomised form of reduced $\mathrm{Fe}$ is poorly absorbed and is not recommended by $\mathrm{WHO}^{(1)}$. This may explain the continued high prevalence of Fe deficiency in Kuwaiti women.

The development of H-reduced NutraFine ${ }^{\mathrm{TM}} \mathrm{RS}$ powder was an attempt to provide a less expensive $\mathrm{H}$-reduced Fe powder with improved bioavailability and good efficacy. The powder had improved solubility in dilute acid by $20 \%$ relative to the previous commercial $\mathrm{H}$-reduced Fe powder (AC-325) (Table 1), but was still only about half that of electrolytic $\mathrm{Fe}$ (Table 1). A similar experimental Fe powder developed by Höganäs called 'Hi-Sol' was previously reported by Lynch \& Bothwell ${ }^{(15)}$ to have an equivalent solubility in dilute acid as electrolytic Fe. For commercial reasons Höganäs chose to commercialise NutraFine ${ }^{\text {TM }}$ RS and not 'Hi-Sol'. Nevertheless, as AC-325 added to wheat flour biscuits in Thailand had been previously reported to have an efficacy of $49 \%$ relative to ferrous sulfate in young women ${ }^{(14)}$, it was still highly surprising that the newly developed NutraFine ${ }^{\mathrm{TM}}$ RS had no efficacy in the present study in Kuwait, even when added at double the amount of $\mathrm{Fe}$ as ferrous sulfate. In contrast, the small particle-sized encapsulated ferrous sulfate was highly efficacious.

Over the 22-week feeding study, the increase in body $\mathrm{Fe}$ stores with $10 \mathrm{mg}$ Fe per $\mathrm{d}$ as encapsulated ferrous sulfate was $3.2 \mathrm{mg} / \mathrm{kg}$ body weight, compared with $1.1 \mathrm{mg} / \mathrm{kg}$ body weight for the women consuming $20 \mathrm{mg} \mathrm{Fe}$ as H-reduced Fe and $0.8 \mathrm{mg} / \mathrm{kg}$ body weight for the control women consuming biscuits with no added Fe. The small but significant increase in body $\mathrm{Fe}$ in the control group was due to a small increase in SF (Table 3). The students were aware of their poor Fe status and, although instructed not to change their eating habits, it is possible that they modified their diet. The total dose of Fe delivered during the intervention was approximately equal to $1.1 \mathrm{~g}$ as $\mathrm{FeSO}_{4}$ or approximately equal to $2.2 \mathrm{~g}$ as NutraFine $^{\mathrm{TM}} \mathrm{RS}$. When these amounts are corrected, by subtracting the increase in body $\mathrm{Fe}$ stores in the control group, the mean increase in total body $\mathrm{Fe}$ due to fortification was $2.4 \mathrm{mg} / \mathrm{kg}$ body weight in the women consuming the encapsulated ferrous sulfate biscuits, and $0.26 \mathrm{mg} / \mathrm{kg}$ body weight for NutraFine $^{\mathrm{TM}}$ RS. When the total increase in body Fe stores (increase in body $\mathrm{Fe}$ stores $(\mathrm{mg} / \mathrm{kg})$ multiplied by mean body weight) is divided by the total $\mathrm{Fe}$ consumed during the study, an estimate can be made of Fe absorption. Using this approach we obtained an Fe absorption of approximately equal to $13.8 \%$ from ferrous sulfate and approximately equal to $0.7 \%$ from $\mathrm{H}$-reduced $\mathrm{Fe}$ over the 22-week trial. This percentage $\mathrm{Fe}$ absorption from encapsulated ferrous sulfate in the present study is somewhat higher than that from the Thailand study ${ }^{(14)}$ recalculated at 20 weeks $(11.3 \%)$; however, in that study, $\mathrm{Fe}$ absorption from $\mathrm{H}$-reduced $\mathrm{Fe}$ (AC-325) at 20 weeks was found to be $5.6 \%$, which is much higher than the $0.7 \%$ found for NutraFine ${ }^{\mathrm{TM}}$ RS in Kuwait. In the present study, it would have been useful to have a direct comparison between NutraFine ${ }^{\mathrm{TM}} \mathrm{RS}$, electrolytic $\mathrm{Fe}$ and A-325 reduced $\mathrm{Fe}$; however, such a large study was not possible with the infrastructure and financial resources available.

Several factors might have contributed to the lack of impact of H-reduced Fe (NutraFine ${ }^{\mathrm{TM}} \mathrm{RS}$ ) on body Fe stores in the present study compared with the relatively good efficacy of $\mathrm{H}$-reduced $\mathrm{Fe}$ (AC-325) reported in the Thai study.
These factors can be divided into general subject factors, which include compliance, dietary habits and baseline $\mathrm{Fe}$ status, and factors influencing the solubility of the Fe powders in the gastric contents during digestion. Compliance was assured in the Thai study by a study coordinator being present during the feeding of the biscuits, whereas in the Kuwait study consumption of the fortified biscuits was not controlled and may have been less than expected; however, since the study design was double-blind and there were no differences in sensory qualities of the snacks, there is no reason to believe that compliance differed between the test groups. Also, although traditional diets are different in Kuwait and Thailand, this should not have influenced Fe absorption as the fortified biscuits were consumed without other foods or drinks.

One factor that may have influenced the results is the different baseline $\mathrm{Fe}$ status of the subjects. The Kuwaiti subjects had negative body Fe stores $(-1 \mathrm{mg} F \mathrm{Fe} / \mathrm{kg}$ body weight) as compared with positive body Fe stores $(+1 \mathrm{mg}$ $\mathrm{Fe} / \mathrm{kg}$ body weight) in the Thai subjects. Data from a recent study suggest that absorption of poorly soluble Fe compounds is less up-regulated by low Fe status than absorption of readily soluble compounds such as ferrous sulfate ${ }^{(26)}$.

Differences in Fe status of study subjects, however, do not appear to be enough to explain the complete lack of efficacy of NutraFine ${ }^{\mathrm{TM}} \mathrm{RS}$, which seems most likely to be due to poor dissolution of the $\mathrm{Fe}$ powder in the gastric contents. Dissolution in the acidic gastric contents is thought to be the main factor governing the relative bioavailability of different elemental Fe powders ${ }^{(15)}$.

Factors that might influence gastric acid dissolution include biscuit composition, the purity and microstructure of the $\mathrm{Fe}$ powder, and impaired gastric acid secretion in the subjects. There were, however, no major differences in the biscuit recipes used in the Kuwaiti and Thai studies, although the recipes varied slightly in fat and sugar content. The biscuits in both studies were made from low-extraction wheat flour that provided only modest amounts of phytic acid $(<0.1 \mathrm{~g} /$ $100 \mathrm{~g}$ ). It also seems unlikely that there were differences in gastric acid secretion between the Kuwaiti and Thai subjects. Helicobacter pylori infections can cause gastric atrophy and greatly reduce gastric acid secretion ${ }^{(27)}$ However, such infections are more prevalent in populations of low socio-economic status, which is not typical of young Kuwaiti women.

Three further factors could explain the poor solubility of NutraFine $^{\mathrm{TM}}$ RS in the gastric juice. These include an improved purity relative to AC-325, a different polycrystalline structure and insoluble oxides formed at the surface during the biscuit baking procedure. The newly developed manufacturing process for H-reduced Fe (NutraFine ${ }^{\mathrm{TM}} \mathrm{RS}$ ) was modified to increase powder porosity and decrease its impurities to a level closer to electrolytic Fe. Data from the manufacturer indicate that the amount of impurities was reduced from $0.47 \%$ in $\mathrm{AC}-325$ to $0.22 \%$ for NutraFine ${ }^{\mathrm{TM}} \mathrm{RS}$. This is supported by data from the X-ray diffraction which show that NutraFine ${ }^{\mathrm{TM}}$ RS contains less iron oxide. While these lower levels of impurities might have in some way decreased the solubility of NutraFine ${ }^{\text {TM }}$ RS relative to A-325 $\mathrm{H}$-reduced Fe, the similarly low levels of impurities in electrolytic Fe powder indicate that this is not the main factor governing solubility. 
Little is known about the polycrystalline structure of $\mathrm{Fe}$ powders produced by different manufacturing processes. However, together with particle size and reactive surface area, polycrystalline structure appears to be a major factor governing Fe powder solubility in dilute acid. Electrolytic Fe powders, irrespective of particle size, are more soluble and have a different polycrystalline structure to reduced $\mathrm{Fe}$ powders. Electrolytic Fe powders are produced by electrolysis of Fe solutions whereas reduced Fe powders are manufactured by heating $\mathrm{Fe}$ ores in kilns at high temperatures for many days. It is possible that the new manufacturing process for NutraFine $^{\mathrm{TM}}$ RS in some way changed the polycrystalline structure of the powder so that it did not dissolve in the gastric contents. A final explanation which needs to be checked is that baking of the biscuits at $200^{\circ} \mathrm{C}$ may have caused insoluble oxides to form on the surface of NutraFine ${ }^{\mathrm{TM}}$ RS. These oxides may have prevented the penetration of the gastric acid and decreased solubility.

In contrast to the poor efficacy of NutraFine ${ }^{\mathrm{TM}} \mathrm{RS}$, the small particle-sized microcapsules of ferrous sulfate greatly improved $\mathrm{Fe}$ status of the Kuwaiti students. Commercially encapsulated ferrous sulfate has previously been reported to be efficacious in salt ${ }^{(28)}$. The novelty of the present study was that the microcapsules were only $40 \mu \mathrm{m}$ in diameter and, unlike the current larger particle-sized commercial encapsulated sulfate, would not be retained on the sieves in the flour mill. Encapsulated ferrous sulfate is preferred over elemental $\mathrm{Fe}$ powders as the Fe fortificant for wheat flour ${ }^{(1)}$. It is better absorbed and, like the elemental Fe powders, it causes no fat oxidation during storage. The present study is the first to confirm the expected high efficacy of encapsulated ferrous sulfate in wheat flour.

Regular encapsulated ferrous sulfate is reported to be about four to ten times the cost of ferrous sulfate. Reducing the size of the ferrous sulfate particles before encapsulation would be expected to add an additional cost. It should be noted that the encapsulated small-sized ferrous sulfate used in the study is an experimental material, which has not been commercialised. Electrolytic $\mathrm{Fe}$ powder is the most expensive elemental $\mathrm{Fe}$ powder and is similar in cost to ferrous sulfate, whereas reduced $\mathrm{Fe}$ and atomised $\mathrm{Fe}$ powders are much cheaper ${ }^{(1,5)}$.

A second objective of the present study was to investigate the potential of wheat flour as a vehicle for co-fortification with $\mathrm{Fe}$ and iodine. There was a significant increase in the median urinary iodine concentration in the group receiving the microencapsulated $\mathrm{Fe}$ and iodine, indicating that the iodine was released from the capsule and was absorbed. This finding is consistent with a previous study where encapsulated ferric pyrophosphate and potassium iodate added to salt improved the iodine status of Moroccan schoolchildren ${ }^{(11,28)}$. Salt is still the preferred vehicle for iodine fortification in most countries, although particularly in poor rural areas of North Africa, the Middle East and South Asia, wheat flour is an important dietary staple and is often centrally processed, whereas salt is provided by many small local producers making it difficult to fortify ${ }^{(11,28)}$. In these regions, wheat flour could be an effective alternative and/or adjunct vehicle for iodine.

In conclusion, the newly developed H-reduced Fe NutraFine $^{\mathrm{TM}} \mathrm{RS}$ is not an efficacious Fe fortificant for wheat flour. As a consequence, electrolytic $\mathrm{Fe}$, at double the Fe concentration of ferrous sulfate, should remain the only elemental
Fe powder recommended for wheat flour fortification ${ }^{(1)}$. The Kuwait wheat flour fortification programme has been advised to use electrolytic Fe. In view of the somewhat surprising result with NutraFine ${ }^{\text {TM }}$ RS, however, it may be worth repeating the study in an alternative population and include a direct comparison of NutraFine ${ }^{\mathrm{TM}}$ RS with electrolytic Fe. In future, Fe powder manufacturers developing new H-reduced Fe powders should aim for solubility values in dilute acid similar to electrolytic Fe before conducting human or animal studies. This appears to be possible, as demonstrated by the Höganäs experimental $\mathrm{Fe}$ powder 'Hi-Sol'(15), which so far has not been accepted as commercially viable. An important key to understanding the solubility of the different Fe powders in the gastric contents is a better knowledge of their polycrystalline structures. Although ferrous sulfate and ferrous fumarate are the first-choice $\mathrm{Fe}$ compounds for wheat flour fortification, addition of these compounds often leads to rancidity during storage or transport. Under these circumstances, encapsulated ferrous sulfate is the next best alternative and, once they are manufactured commercially, the newly developed small particle-sized microcapsules of $\mathrm{Fe}$ and iodine offer the possibility of fortifying wheat flour in a way which will improve both Fe and iodine status.

\section{Acknowledgements}

The present study was supported by the Kuwaiti Flour Mills and Bakeries Company (Kuwait City, Kuwait), the International Atomic Energy Agency (Vienna, Austria), ETH Zurich (Switzerland), Medicor Foundation (Liechtenstein) and the Kuwait Institute for Scientific Research (KISR) (Kuwait City, Kuwait).

We thank the faculty members and the college students for their participation in the study. At the Swiss Federal Institute of Technology (Zurich, Switzerland), we thank E. Windhab for the facilities and support to optimise the microcapsules, C. Zeder for the help with the technical and laboratory analysis, J. Nuessli for her support in the sensory evaluation of the biscuits, and R. Buechel for the X-ray pattern measurements. We thank the Kuwaiti Flour Mills and Bakeries Company in Kuwait for the technical advice and support in producing and supplying the fortified biscuits.

At the Kuwait Institute for Scientific Research (KISR), we thank, in alphabetic order, A. Ali, A. Al-Azmi, S. Al-Hamli, J. Al-Saqer, B. Dashti and I. Ilyan for their help in conducting the study. At the Ministry of Health in Kuwait and associated Al-Sabah Hospital, we thank the dietitians and the technical staff for their help in conducting the laboratory analysis.

We also thank L. Davidsson (International Atomic Energy Association) for the support for the study, M. Haldimann at the Ministry of Public Health, Switzerland in conducting the biscuit and capsule iodine content measurements, and W. Jahn (Dr Paul Lohmann GmbH KG, Emmertal, Germany) for the supply of the dried micronised $\mathrm{FeSO}_{4}$.

R. B., M. B. Z., S. N. Al-H., N. Al-H. and R. F. H. participated in the design of the study. R. B., M. B. Z., N. P. and R. F. H. developed the microcapsules. S. N. Al-H., R. B. and M. B. Z. conducted the study and T. Z. and Y. K. helped in collecting the data. R. B. and M. B. Z. wrote the first draft of the manuscript. All of the authors edited the manuscript. 
None of the authors had a conflict of interest in relation to the study.

\section{References}

1. World Health Organization \& Food and Agriculture Organization (2006) Guidelines on Food Fortification with Micronutrients. Geneva: WHO.

2. World Health Organization (2004) Iodine Status Worldwide: WHO Global Database on Iodine Deficiency. Geneva: WHO.

3. United Nations Children's Fund, World Health Organization, United Nations University et al. (1998) Preventing Iron Deficiency in Women and Children: Background and Consensus on Key Technical Issues and Resources for Advocacy, Planning and Implementing National Programmes. Boston, MA: International Nutrition Foundation.

4. Hurrell RF (2002) Fortification: overcoming technical and practical barriers. J Nutr 132, Suppl. 4, 806S-812S.

5. Hurrell R, Bothwell T, Cook JD, et al. (2002) The usefulness of elemental iron for cereal flour fortification: a SUSTAIN Task Force report. Sharing United States Technology to Aid in the Improvement of Nutrition. Nutr Rev 60, 391-406.

6. Hurrell R (1999) Iron. In The Mineral Fortification of Foods, pp. 54-93 [R Hurrell, editor]. Leatherhead, UK: Leatherhead Food RA.

7. de Benoist B, McLean E, Andersson M, et al. (2008) Iodine deficiency in 2007: global progress since 2003. Food Nutr Bull 29, 195-202.

8. Andersson M, Takkouche B, Egli I, et al. (2005) Current global iodine status and progress over the last decade towards the elimination of iodine deficiency. Bull World Health Organ $\mathbf{8 3}$, $518-525$.

9. Hurrell RF, Furniss DE, Burri J, et al. (1989) Iron fortification of infant cereals: a proposal for the use of ferrous fumarate or ferrous succinate. Am J Clin Nutr 49, 1274-1282.

10. Zimmermann MB (2004) The potential of encapsulated iron compounds in food fortification: a review. Int J Vitam Nutr Res 74, 453-461.

11. Zimmermann MB, Wegmueller R, Zeder C, et al. (2004) Dual fortification of salt with iodine and micronized ferric pyrophosphate: a randomized, double-blind, controlled trial. Am J Clin Nutr 80, 952-959.

12. Zimmermann MB, Wegmueller R, Zeder C, et al. (2004) Triple fortification of salt with microcapsules of iodine, iron, and vitamin A. Am J Clin Nutr 80, 1283-1290.

13. World Health Organization (2008) WHO Expert Consultation on Salt as a Vehicle for Fortification, Luxembourg, 21-22 March 2007. Geneva: WHO.

14. Zimmermann $\mathrm{MB}$, Winichagoon $\mathrm{P}$, Gowachirapant $\mathrm{S}$, et al. (2005) Comparison of the efficacy of wheat-based snacks fortified with ferrous sulfate, electrolytic iron, or hydrogenreduced elemental iron: randomized, double-blind, controlled trial in Thai women. Am J Clin Nutr 82, 1276-1282.

15. Lynch SR \& Bothwell T (2007) A comparison of physical properties, screening procedures and a human efficacy trial for predicting the bioavailability of commercial elemental iron powders used for food fortification. Int J Vitam Nutr Res 77, $107-124$

16. Wegmuller R, Zimmermann MB, Buhr VG, et al. (2006) Development, stability, and sensory testing of microcapsules containing iron, iodine, and vitamin A for the use in food fortification. J Food Sci 71, 181-187.

17. Pino S, Fang SL \& Braverman LE (1996) Ammonium persulfate: a safe alternative oxidizing reagent for measuring urinary iodine. Clin Chem 42, 239-243.

18. Pino S, Fang SL \& Braverman LE (1998) Ammonium persulfate: a new and safe method for measuring urinary iodine by ammonium persulfate oxidation. Exp Clin Endocrinol Diabetes 106, Suppl. 3, S22-S27.

19. Makower RU (1970) Extraction and determination of phytic acid in beans (Phaseolus vulagaris). Cereal Chem 47, 288-296.

20. Cook JD, Flowers CH \& Skikne BS (2003) The quantitative assessment of body iron. Blood 101, 3359-3364.

21. Haldimann M, Eastgate A \& Zimmerli B (2000) Improved measurement of iodine in food samples using inductively coupled plasma isotope dilution mass spectrometry. Analyst 125, 1977-1982.

22. Wegmüller R, Zimmermann MB \& Hurrell RF (2003) Dual fortification of salt with iodine and encapsultaed iron compounds: stability and acceptability testing in Morocco and Côte d'Ivoire. J Food Sci 68, 2129-2135.

23. Eid N, Al-Hooti S, Bourisly N, et al. (1986) Anaemia in school children: a preliminary study. J Kuwait Med Assoc 20, 39-43.

24. Al-Awadi F, Amine E \& Goulam Z (1995) Assessment of the Nutritional Status of Vulnerable Groups in Kuwait. Shaab, Kuwait: Food and Nutrition Administration Ministry of Health.

25. Jackson RT \& Al-Mousa Z (2000) Iron deficiency is a more important cause of anemia than hemoglobinopathies in Kuwaiti adolescent girls. J Nutr 130, 1212-1216.

26. Moretti D, Zimmermann MB, Wegmuller R, et al. (2006) Iron status and food matrix strongly affect the relative bioavailability of ferric pyrophosphate in humans. Am J Clin Nutr 83, $632-638$

27. Sarker SA, Davidsson L, Mahmud H, et al. (2004) Helicobacter pylori infection, iron absorption, and gastric acid secretion in Bangladeshi children. Am J Clin Nutr 80, 149-153.

28. Zimmermann MB, Zeder C, Chaouki N, et al. (2003) Dual fortification of salt with iodine and microencapsulated iron: a randomized, double-blind, controlled trial in Moroccan schoolchildren. Am J Clin Nutr 77, 425-432. 